\title{
Neuropsychological profile of children and adolescents with the 22q11.2 microdeletion
}

\author{
Michael Woodin, $P h D^{1}$, Paul P. Wang, $M D^{1}$, David Aleman, $M S^{2}$, Donna McDonald-McGinn, $M S^{3}$,
} Elaine Zackai, $M D^{3}$, and Edward Moss, $P h D^{4}$

\begin{abstract}
Purpose: Patients with one of the 22q11.2 deletion syndromes provide a unique opportunity to research the interface between genetics and brain-behavior relationships. This study investigates the neuropsychological characteristics and behavioral phenotype of children with this deletion syndrome. Methods: We report updated findings from descriptive and nonparametric analyses of neuropsychological data from 80 children with the 22q11.2 deletion. Results: The subjects showed higher verbal than nonverbal IQ scores, assets in verbal memory, and deficits in the areas of attention, story memory, visuospatial memory, arithmetic performance relative to other areas of achievement, and psychosocial functioning. Conclusion: Children with 22q11.2 deletion syndromes exhibit a behavioral phenotype reflective of nonverbal learning disabilities, concomitant language deficits, and social-emotional concerns. Genetics in Medicine, 2001:3(1):34-39.
\end{abstract}

Key Words: velocardiofacial syndrome, chromosome 22, 22q11.2, neuropsychology, behavioral genetics, nonverbal learning disabilities, learning disabilities, language impairment, speech disorders

Over the past several decades, there has been a marked increase in the integration of behavioral genetics with neuropsychological lines of inquiry. By engaging in such research, it is hoped that greater specificity will be gained in the attempt to establish links between particular genetic or chromosomal disorders and corresponding distinct neurocognitive and behavioral characteristics expressed by affected individuals. Through such efforts, increasingly "pure" behavioral phenotypes have been constructed for well-known genetic disorders such as neurofibromatosis, Type $\mathrm{I}^{1,2}$ (NF-1) and Williams syndrome (WS). ${ }^{3-5}$ Each of these disorders has a fairly long history of inquiry. NF-1 was first described in the late $1800 s^{6}$ and the identification of WS occurred between 1952 and 1961.7-9 In contrast, only recently has it been determined that both the velocardiofacial syndrome (VCFS) and the DiGeorge anomalad result from a submicroscopic hemizygous deletion at chromosome 22q11.2. ${ }^{10-13}$ As such, while initial attempts at identifying a behavioral phenotype for this group have occurred, a comparatively smaller body of research has focused upon the neuropsychological characteristics of children and adolescents with the 22q11.2 deletion..$^{14-17}$ The purpose of this report is to present updated and expanded findings that will contribute

\footnotetext{
From the ${ }^{1}$ Division of Child Development, Department of Psychology, the Children's Hospital of Philadelphia; ${ }^{2}$ Divisions of Child Development and Neurology, Department of Pediatrics, University of Pennsylvania School of Medicine and Children's Hospital of Philadelphia; ${ }^{3}$ Division of Human Genetics and Molecular Biology, Department of Pediatrics, University of Pennsylvania School of Medicine and Children's Hospital of Philadelphia; ${ }^{4}$ Department of Psychiatry, University of Pennsylvania School of Medicine, Philadelphia, Pennsylvania. Michael Woodin, PhD, Rush Neurobehavioral Center, 9701 Knox Avenue, Suite 102, Skokie, IL 60076.
}

Received: August 24, 2000.

Accepted: November 1, 2000. toward the further delineation of a behavioral phenotype for this disorder. Our aim is to increase awareness by providing clinical benchmarks for reference and use when consulting with or counseling patients with chromosome 22q11.2 deletion syndromes.

The 22q11.2 deletion syndrome is an increasingly common genetic disorder affecting at least 1 in 4,000-4,500 live births. ${ }^{18}$ The phenotypic expression of VCFS is quite varied. ${ }^{19,20}$ Medical conditions associated with the disorder include over 180 clinical features such as hypocalcemia, conotruncal cardiac anomaly, velopharyngeal incompetence, cleft palate, $\mathrm{T}$ cell abnormalities (immunodeficiencies), and characteristic facies. ${ }^{18}$ In addition, central nervous system (CNS) deficits and brain morphologic changes have also been identified within this group. ${ }^{21-24}$ Findings such as this are likely related to reports of mild cognitive impairment, learning disorders, nonverbal learning disabilities, moderate to mild mental retardation, speech and language deficits, and behavior and mood disorders within the group. ${ }^{14,25,26}$

Examinations into the behavioral and psychiatric profile of individuals with the 22q11.2 deletion have yielded mixed results. Disorders identified in this population include attentiondeficit/hyperactivity disorder (ADHD), ${ }^{27,28}$ oppositional defiant disorder, separation anxiety disorder, specific phobias, generalized anxiety disorder, depressive disorders, ${ }^{28}$ bipolar mood disorders, ${ }^{27,29}$ schizophrenia, ${ }^{30}$ obsessive-compulsive features, ${ }^{27,31}$ and occasional reports of autism. ${ }^{32}$ Within the pediatric population, limited information ${ }^{33,34}$ is available regarding their psychosocial profile as assessed through parent behavioral ratings. While externalizing characteristics such as aggression and conduct problems have not arisen as a primary feature of those in this group, the research has indicated that 
children with the 22q11.2 deletion are at-risk for developing internalizing characteristics such as anxiety, depression, withdrawal, obsessions, compulsions, and socialization deficits.

Through the work of three major research groups, ${ }^{14,25,26,35} \mathrm{a}$ prototypical cognitive and educational pattern for children and adolescents with the 22q11.2 deletion has been identified and replicated. Specifically, the test pattern delineated involves full-scale IQ scores for the group that range from moderately deficient to average, with a significant difference noted in favor of verbal IQ over nonverbal or performance IQ. In addition, it has been noted across researchers that the 22q11.2 group also evidences basic reading and spelling skills that are superior to arithmetic skills.

A unique contribution was offered by Moss and his colleagues ${ }^{14-16,35}$ who also determined that, although the verbal intellectual abilities were an area of relative strength for those with the 22q11.2 deletion, group performance on more specific measures of receptive and expressive language skills was significantly $(P \leq 0.001)$ lower than verbal IQ. These findings were present even when patients with mental retardation were excluded from the data pool, indicating that this was not simply a function of reduced intellectual capacity.

The data reviewed above have indicated that patients with the 22q11.2 deletion display a distinctive and complex neuropsychological pattern of performance that includes deficits in visual-spatial processing, arithmetic performance, and language functions. Subsequent analyses have also identified weaknesses in the areas of language, ${ }^{14,36}$ attention, working memory, and executive functioning, ${ }^{16}$ visual-spatial memory, ${ }^{37}$ arithmetic and visuospatial short-term memory, ${ }^{15}$ and psychosocial functioning. ${ }^{33,34}$ Assets have also been indicated to occur within the areas of verbal ability, rote processing, verbal memory, reading, and spelling. Such a profile composes many of the benchmark characteristics of what is termed the syndrome of nonverbal learning disabilities (NLD). ${ }^{38}$ This syndrome has subsequently been used to characterize and map the neurocognitive profiles of children with other genetic and developmental disorders such as Asperger's syndrome, de Lange syndrome, Turner's syndrome, and Sotos syndrome. Rourke ${ }^{38}$ hypothesized that children with the 22q11.2 deletion may manifest the NLD syndrome as a result of white matter irregularities. Although they noted that "there is currently no hard evidence of white matter pathology in VCFS," the authors offered the conjecture that disruptions may occur during the early period of cellular proliferation and migration. Since the cardiac and ocular defects that occur in this syndrome are thought to arise from the abnormal migration of the neural crest, white matter pathology may also arise in those with the 22q11.2 microdeletion as a result of this same phenomenon. To this end, Moss and his colleagues ${ }^{14}$ asserted that the IQ and academic profile approximated NLD and that similar learning problems in arithmetic manifest in many reports on children with developmental learning disabilities thought to arise from right hemispheric dysfunction.

While findings reviewed have been helpful in initiating inferences about specific brain-behavior relationships, the IQ and achievement measures generally used are gross composites of a variety of cognitive abilities. As such, it is difficult to elucidate upon the differential involvement and/or impairment of particular neural circuits or specific brain regions within the 22q11.2 population. However, recent neuroimaging studies have documented morphological changes in specific brain regions of patients with 22q11.2 deletions. Moreover, the results from these studies seem to offer some support for the white matter hypothesis and may serve to further elucidate the specific brain-behavior relationships underlying this genetic syndrome. Initial neuroradiological findings within a limited sample from this population included agenesis of the corpus callosum, an undersized cerebellum, small pituitary gland, and periventricular white matter abnormalities. ${ }^{21,22}$ Later research documented enlargement of the Sylvian fissure and opercular underdevelopment in infants with the 22q11.2 microdeletion. ${ }^{23}$ In addition, results from a volumetric MRI study ${ }^{24}$ revealed a decrease in overall brain volume due to an attenuation in both gray and white matter volumes, enlargement of the frontal lobe relative to overall brain volume reduction, a decrease in left parietal lobe tissue volume, a decrease in right cerebellar tissue, and higher rates of microcephaly. Moreover, Kates and colleagues ${ }^{39}$ also documented significantly reduced posterior brain volume for VCFS patients relative to normal controls, with white matter loss more significantly implicated in the left occipital (19.3\%) and left parietal (13.9\%) regions than in the frontal lobe (under 5\%) when compared to an ageand gender-matched control cohort. Many of these changes in brain structure can be postulated to relate to the specific cognitive deficits exhibited by the group in the areas of executive function, working memory, visuospatial skill, language, specific forms of memory, and math performance. However, as Eliez and his associates ${ }^{24}$ note, while such studies add incremental knowledge to the body of research in this area, limitations to generalization are posed due to small group size and multiple statistical comparisons. With further research, greater associations between such morphological indices and brainbehavior relationships may be ascertained.

The present study was undertaken to replicate and further extend the work detailed above in order to gain greater specificity regarding the emerging behavioral phenotype of children and adolescents with confirmed 22q11.2 microdeletions along more discrete domains of neuropsychological functioning. We sought to replicate and extend previous cognitive and neuropsychological findings during the present study that would confirm the presence of an NLD profile in this sample. In addition, consistent with the NLD syndrome, we hypothesized that deficits would be exhibited in the areas of executive functioning and working memory. It was also anticipated that memory performance for this group would be characterized by better developed rote verbal memory capability in contrast to poorer visual-spatial memory. Moreover, while rote verbal memory was expected to be strong, we hypothesized that the group would exhibit deficits when engaged in a more complex verbal memory test requiring greater attention, synthesis, and language integration skills. Finally, since limited informa- 
$\operatorname{tion}^{33,34}$ is available regarding the psychosocial profile the pediatric population as assessed through parent behavioral ratings, we sought to confirm the presence of social-emotional deficits and hypothesized a greater occurrence of attention, social, and internalizing concerns with minimal group elevations in the areas of externalizing problems.

\section{METHODS}

All participants were recruited as part of a larger multidisciplinary study of the developmental, neurobehavioral, and medical characteristics of the 22q11.2 microdeletion. Confirmation of the genetic diagnosis was made through fluorescence in situ hybridization (FISH) studies. Eighty-one consecutively referred patients were administered a comprehensive neuropsychological examination by a pediatric neuropsychologist. Whole group analyses were conducted for broad estimates of intellectual ability. A subset of 50 subjects who were 6-17 years in age underwent a more complete neuropsychological and psychosocial assessment for domain-specific analyses. Descriptive data for the full cohort and school-aged subset are presented in Table 1 . Sex was evenly distributed across both samples with no significant differences noted controlling for sex in any of the analyses conducted. In addition, previous research ${ }^{23}$ has indicated that over two-thirds of the 22q11.2 patients received special educational assistance. Our findings confirmed this estimate and provide further data regarding the percentages of individuals receiving full- or part-time special educational assistance and full time regular education. These results are also fully represented in Table 1.

The primary measures utilized assessed intelligence, academic achievement, executive function, working memory, memory, and psychosocial functioning. All participants were administered the age-appropriate Wechsler intelligence test battery: the Wechsler Intelligence Scale for Children-Third Edition, WISC-III ${ }^{40}$ (for those aged 6 through 16 years, 11 months), the Wechsler Preschool and Primary Scales of Intelligence-Revised, WPPSI-R ${ }^{41}$ (for children up to 6 years of age), and the Wechsler Adult Intelligence Scale, WAIS ${ }^{42}$ (for ages 17 years and older). These tests generate full-scale IQ,

Table 1

Sample descriptive characteristics

\begin{tabular}{lcc}
\hline & Full cohort & $\begin{array}{c}\text { School-age } \\
\text { sample }\end{array}$ \\
\hline Sample size $(n)$ & 81 & 50 \\
Age & $10.6 \pm 3.7$ & $10.3 \pm 3.2$ \\
Male & $41(51.0 \%)$ & $24(48.0 \%)$ \\
Female & $40(49.0 \%)$ & $26(52.0 \%)$ \\
FT special education & $32(39.5 \%)$ & $15(30.0 \%)$ \\
PT special education & $34(42.0 \%)$ & $25(50.0 \%)$ \\
Regular education & $15(18.5 \%)$ & $10(20.0 \%)$ \\
\hline
\end{tabular}

FT, full-time; PT, part-time. verbal IQ, and performance or nonverbal IQ estimates. Participants were also given measures of broad reading, spelling, and mathematics achievement. For those aged 6 through 19, the Wechsler Individual Achievement Test ${ }^{43}$ was utilized, while those who were 20 years or older were given the WoodcockJohnson Tests of Achievement-Revised. ${ }^{44}$ Executive function and working memory was assessed through administration of the Trail-Making Test, Forms A and B, ${ }^{45}$ and the Freedom from Distractibility Index from the WISC-III. To examine specific memory performance, participants aged 5 through 17 years, 11 months, were administered the Verbal Learning, Story Memory, and Design Memory subtests of the Wide Range Assessment of Memory Learning, WRAML. ${ }^{46}$ Psychosocial functioning was examined through administration of the Achenbach Child Behavior Checklist, CBCL, ${ }^{47}$ an objective survey of behavior and mood completed by mothers of participants aged 6 through 17.

Descriptive and nonparametric procedures (Wilcoxon signed ranks) were used for statistical analyses, with a required probability of $P \leq 0.05$ required for all planned comparisons. For consistency of presentation, all cognitive, neuropsychological and educational scores will be reported in Standard Score format (mean $=100 ; S D=15)$ and psychosocial scores will be reported in $\mathrm{T}$-score format $($ mean $=50 ; \mathrm{SD}=10)$.

\section{RESULTS}

\section{Intelligence/cognitive ability}

Overall, both the full cohort and school-aged sample evidenced full-scale IQ scores ranging from moderately mentally deficient to average. However, full-scale IQ is an estimate based upon their combined verbal and performance IQ scores. For both of our groups, significant differences were noted between these two indices (both at $P \leq 0.000$ ) and across the full range of intelligence, with verbal IQ in the low average range and performance IQ within the borderline range. To specify the pattern of neuropsychological results across one schoolaged sample, all further analyses were conducted with the subset of 50 participants. IQ scores are presented in Table 2. The number of children exhibiting verbal $>$ performance discrepancies within our sample is greater than would be expected in the general population.

\section{Academic achievement}

In the area of academic achievement, findings revealed a significant difference $(Z=-5.329, P \leq 0.000)$ for the group between their nearly average performance in the area of broad reading and borderline functioning in the area of broad math. Table 2 includes the mean scores that the group achieved in these areas and the specific pattern of academic functioning is depicted in Figure 1. Patients showed significantly better developed $(Z=-2.991, P \leq 0.003)$ word reading skills in comparison to reading comprehension abilities but evidenced no significant differences between tasks of paper-and-pencil arithmetic and math reasoning. Spelling abilities were within the low average range, similar to broad reading skills. 
Table 2

Intelligence, achievement, memory, and executive function means and standard deviations $(N=50)$

\begin{tabular}{lcc}
\hline Measure & Mean & SD \\
\hline Full Scale IQ & 76 & 12.70 \\
Verbal IQ & 83 & 14.12 \\
Performance IQ & 73 & 12.42 \\
Verbal Comprehension Index & 85 & 14.28 \\
Perceptual Organization Index & 73 & 12.42 \\
Freedom From Distractibility Index & 81 & 14.56 \\
Broad Reading & 88 & 12.75 \\
Broad Math & 79 & 12.91 \\
Spelling & 89 & 12.20 \\
Design Memory—Delayed Recall & 87 & 14.56 \\
Verbal Learning—Total Score & 97 & 15.81 \\
Verbal Learning—Delayed Recall & 94 & 15.90 \\
Story Memory-Delayed Recall & 81 & 13.45 \\
Trails A & 90 & 27.02 \\
Trails B & 69 & 32.67 \\
\hline
\end{tabular}

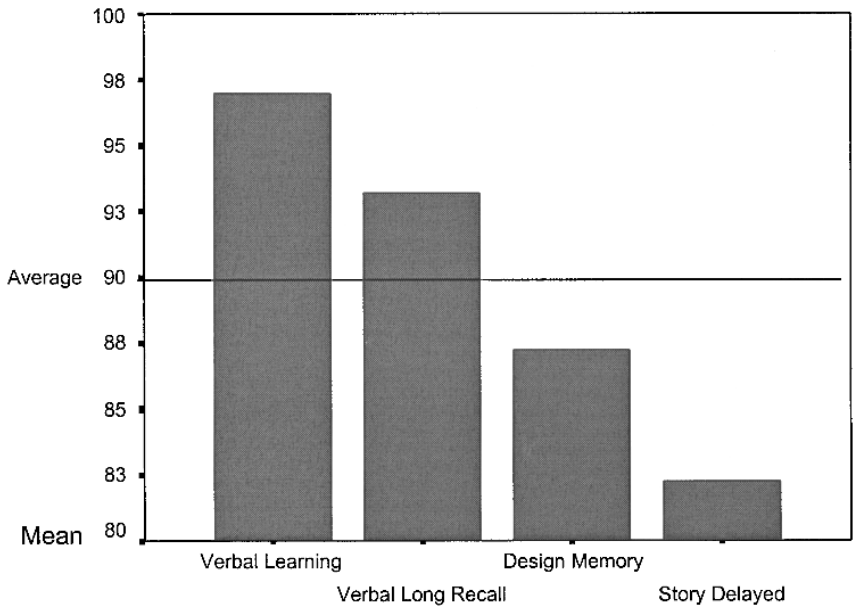

Fig. 1 Profile of memory scores $(N=50)$.

\section{Executive function and working memory}

Scores for performance in this area are presented in Table 2. As a group, the 22q11.2 school-aged sample evidenced average ability on Trails A, a test of brief, focused attention. However, a significant difference $(\mathrm{Z}=-3.539, P \leq 0.000)$ was noted between their better ability on this measure and that involving Trails B, a similar task that also requires them to shift attention and exhibit cognitive flexibility in order to meet its competing demands. In addition, relative to pure verbal cognitive ability as measured through the WISC-III Verbal Comprehension index, the group performed significantly $(Z=-1.930, P \leq 0.05)$ more poorly on tasks of verbal attention and working memory as indicated by the lower group mean attained on the WISC-III Freedom From Distractibility index.

\section{Memory}

Memory results are presented in Table 2. Rote verbal memory was an area of relative strength for the school-aged $22 \mathrm{q} 11.2$ group, as they exhibited average performance on the Verbal Learning subtest of the WRAML. In this subtest, the patient is instructed to learn a list of 16 unrelated words over four learning trials, after which a long-delay recall trial is also given. Sample scores ranged from moderately deficient to superior. It is remarkable to note that while $62 \%$ of this sample attained IQ estimates within the borderline to moderately mentally deficient range, a full $72 \%$ of the same group scored within the low average to very superior range in the area of verbal memory. As such, this is an area of remarkable strength for most individuals within the group. While patients performed well on this task of rote verbal learning and memory, there was a significant discrepancy $(Z=-2.525, P \leq 0.01)$ between their average score in this area and their low average score on the visual-spatial design memory subtest of the WRAML. Further analysis of their verbal memory indicated that, although they fared with the average range on the long delay portion of the rote verbal learning task, when contrasted against a more complex and meaningful task of delayed story memory from the WRAML, they performed within the borderline range. This difference was statistically significant $(\mathrm{Z}=-3.611, P \leq 0.000)$. Thus, rote verbal learning and memory is an area of strength for this group, while visual-spatial memory and more complex forms of verbal recall are areas of relative weakness. A comparison of memory scores for the sample is presented in Figure 1.

\section{Psychosocial functioning}

We examined the Achenbach Child Behavior Checklist (CBCL) profiles completed by the parents of the children and adolescents within the subset of school-aged children. At-risk elevations (at or above a T-score of 60) were revealed for the group mean Total Composite $(63 \pm 9.97)$ and Internalizing Problems Composite $(63 \pm 12.12)$. There were also at-risk elevations on specific clinical subscales assessing behaviors associated with withdrawal $(60 \pm 8.9)$, somatic complaints (63 $11.67)$, anxiety/depression (62 \pm 9.5$)$, social problems $(65 \pm$ $11.35)$, thought problems $(63 \pm 10.12)$, and attention problems $(67 \pm 10.18)$. Clinical scales for aggression and delinquency were within normal limits. Results of nonparametric Wilcoxon Signed Ranks test indicated significantly higher scores $(Z=-4.882, P<0.000)$ in the broad area of internalizing problems (i.e., anxiety/depression, withdrawal, somatic complaints) versus externalizing problems (i.e., aggression and delinquency). The profile of psychosocial functioning for this sample is presented in Figure 2.

\section{DISCUSSION}

The 22q11.2 deletion syndromes are characterized by an atypical neuropsychological profile across multiple domains, and they ultimately display a cognitive profile characterized by significantly higher verbal IQ than performance or nonverbal 


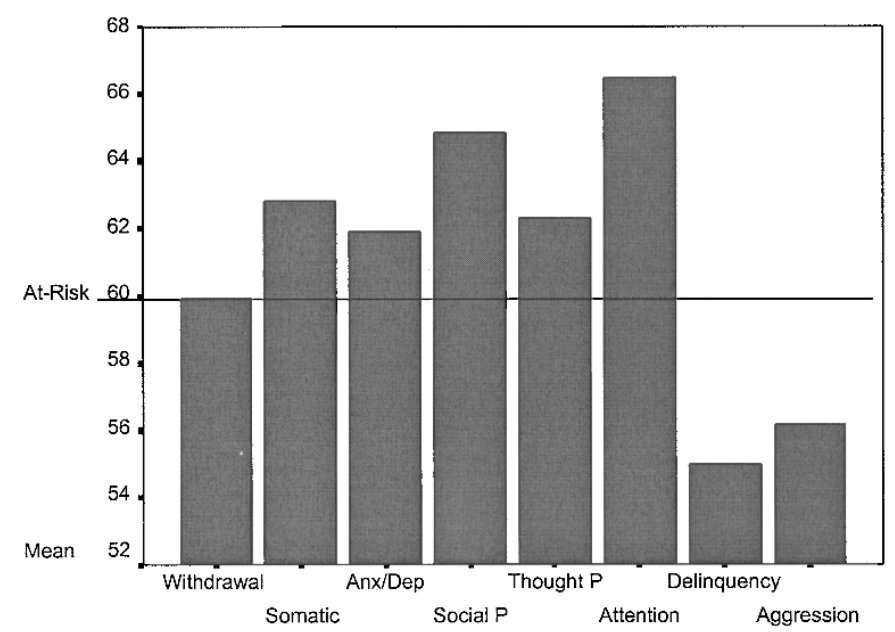

Fig. 2 Pattern of psychosocial functioning $(N=50)$.

IQ scores. In addition, they exhibit assets or relative strengths in the areas of verbal skills, rote verbal learning and memory, reading decoding, and spelling. Deficits, however, are found in areas of nonverbal processing, visual-spatial skills, complex verbal memory, attention, working memory, visual-spatial memory, and mathematics. As such, they evidence a profile that closely approximates NLD and suggests either right hemispheric dysfunction, white matter anomalies, and/or possible involvement of specific brain regions as elucidated through current neuroimaging efforts.

Our data indicate that individuals with 22q11.2 deletions demonstrate NLD characteristics, but that their "disability" is not limited to "nonverbal" functions. Verbal abilities as measured through IQ tests such as the WISC-III represent the formed or "crystallized" products of schooled or taught knowledge the child has gained through their rote learning and/or repeated cultural experiences and interactions at home or through the classroom. These include knowledge of words, factual information, the ability to draw associations between two words, and their understanding of practical situations. Individuals from this population show a unique strength in their ability to learn and retain such verbal information that is presented over repeated occasions. In contrast, more fluid abilities such as executive functions and complex language processes involve the ability to efficiently and automatically understand, structure, and synthesize information. As such, while rote abilities are an area of strength, difficulties with attention and more complex forms of information are likely tied to deficits in the ability to engage in tasks involving story memory or more intricate forms of verbal processing.

Moreover, difficulties arising from the nonverbal deficits that were exhibited by this sample are often associated with and/or exacerbate psychosocial difficulties. Within the present sample, clinical elevations were detected in the areas of overall behavior, internalizing problems, anxiety/depression, thought problems, attention problems, withdrawal, somatic complaints, and social problems. However, clinical scales for externalizing behaviors such as conduct problems and aggression were within normal limits. Since prior studies of adults and children with 22q11.2 deletion syndromes have documented a markedly increased frequency of psychiatric disorders, monitoring levels of concern in these psychosocial areas is paramount.

It is important to note that while these patterns of performance represent an emergent neuropsychological profile and behavioral phenotype, one of the most salient features of the 22q11.2 deletion syndrome is the substantial scatter and wide variability exhibited by each individual within the group. This variability is generally greater than would be found in most children. By conducting research such as this, we gain greater specificity in describing and documenting the particular set of assets and deficits that should be expected in working with those who have the 22q11.2 microdeletion.

In turn, this information has led to greater precision in prescribing educational, psychological, and psychiatric interventions and treatments. ${ }^{52,53}$ For instance, classroom accommodations for visual-spatial difficulties can be made, and strategies can be implemented to help automatize, script, and structure their learning so that verbal assets can be accentuated. Findings from this research may also be used to forward utilization of specific published curriculum in the areas of reading and math and contribute to seminal efforts in the area of program development and interventions for children with NLD. ${ }^{38}$

To offer greater specificity regarding the neuropsychological profile of those with the 22q11.2 deletion and offer targeted remedial and psychosocial interventions discrete functions should continue to be examined within this population. In addition, efforts must continue to associate findings from neuroimaging studies with the neuropsychological deficits and the brain-behavior relationships demonstrated, which impact learning and school performance. Such information regarding their cognitive and social-emotional profile will help to drive development of school techniques. Furthermore, as suggested by those involved with behavioral genetics and behavioral phenotyping, ${ }^{48-51}$ to construct a behavioral phenotype from which inferences can be made about the unique and homogeneously distinctive nature of the 22q11.2 syndromes, efforts should be begun to compare the performance of those from this population against that of nonaffected siblings and/or other groups of children and adolescents who display a pattern approximating a nonverbal learning disability.

\section{Acknowledgments}

This study was supported by funds from the National Institutes of Health Grant VCFS DC02027, and SCOR HL62177, and the NICDC, MRRC HD26979.

\section{References}

1. Dilts CV, Carey JC, Kircher JC, Hoffman RO, Creel D, Ward K, Clark E, Leonard CO. Children and adolescents with neurofibromatosis 1: a behavioral phenotype. J Dev Behav Pediatr 1996;17:229-239.

2. Kayl AE, Moore BD. Behavioral phenotype of neurofibromatosis, Type 1. Ment Retard Dev Disabil Res Rev 2000;6:117-124. 
3. Bellugi U, Mills D, Jernigan T, Hickok G, Galaburda A. Linking cognition, brain structure, and brain function in Williams Syndrome. In: Tager-Flusberg H, editor. Neurodevelopmental disorders. Cambridge, MA: The MIT Press, 1999:111-136.

4. Mervis CB, Klein-Tasman BP. Williams Syndrome: cognition, personality, and adaptive behavior. Ment Retard Dev Disabil Res Rev 2000;1900:6:148-158.

5. Wang PP, Hesselink JR, Jernigan TL, Doherty S, Bellugi U. Specific neurobehavioral profile of Williams' syndrome is associated with neocerebellar hemispheric preservation. Neurology 1992;42:1999-2002.

6. Crump T. On multiple fibromas of the skin and their relationship to multiple neuromas. Translation of case reports by F. v. Recklinghausen. In: Riccardi VM, Mulvihill J, editors. Neurofibromatosis: genetics, cell biology, and biochemistry, Vol 23. New York: Raven Press, 1981: 259-275.

7. Fanconi G, Giradet P, Schlesinger B, Butler N, Black JA. Chronische hypercalcaemie, kominiert mit osteosklerose, hyperasotaemie, minderwuchs and kongenitalen missbildungen. Helv Paediatr Acta 1952;314-334.

8. Payne WW. The blood chemistry in idiopathic hypercalcaemia. Arch Dis Child 1952; 27:302-303.

9. Williams J, Barratt-Boyes BG, Lowe JB. Supravalvular aortic stenosis. Circulation 1961;24:1311-1318

10. Driscoll DA, Spinner NB, Budarf ML, McDonald-McGinn DM, Zackai EH, Goldberg RB, Shprintzen RJ, Saal HM, Zonana J, Jones MC. Deletions and microdeletions of 22q11.2 in velo-cardio-facial syndrome. Am J Med Genet 1992;44:261-268.

11. Driscoll DA, Salvin J, Sellinger B, Budarf ML, McDonald-McGinn DM, Zackai EH Prevalence of 22q11 microdeletions in DiGeorge and velocardiofacial syndromes: implications for genetic counseling and prenatal diagnosis. J Med Genet 1993;30: 813-817.

12. Scrambler PJ, Carey AH, Wyse RK, Roach S, Dumanski JP, Nordenskjold M, Williamson R. Microdeletions within 22q11 associated with sporadic and familial DiGeorge syndrome. Genomics 1991;10:201-206.

13. Carlson C, Sirotkin H, Pandita R, Goldberg R, McKie J, Wadey R, Patanjali SR, Weissman SM, Anyane-Yeboa K, Warburton D, Scambler P, Shprintzen R, Kucherlapati R, Morrow BE. Molecular definition of 22q11 deletions in 151 velo-cardiofacial syndrome patients. Am J Med Genet 1997;61:620-629.

14. Moss E, Batshaw ML, Solot CB, Gerdes M, McDonald-McGinn DM, Driscoll D, Emanuel BS, Zackai EH, Wang PP. Psychoeducational profile of the 22q11.2 microdeletion: a complex pattern. J Pediatr 1999;134:193-198.

15. Wang PP, Woodin MF, Kreps-Falk R, Moss EM. Research on behavioral phenotypes: velocardiofacial syndrome (deletion 22q11.2). Dev Med Child Neurol 2000; 42:422-427.

16. Woodin MF, Wang PP, Bearden C, McDonald-McGinn D, Zackai E, Emmanuel B, Moss E. Attention, working memory, and executive functions in children and adolescents with velocardiofacial syndrome: patterns, profiles, and presentation. Paper presented at the Annual Meeting of the International Neuropsychological Society; Denver, CO. February 12-15, 2000.

17. Swillen A, Vandeputte L, Cracco J, Maes B, Ghesquière P, Devriendt K, Fryns J. Neuropsychological, learning and psychosocial profile of primary aged children with the VCFS (22q11 deletion): evidence for a nonverbal learning disability? Child Neuropsychol 2000;6:1-12.

18. Tezenas Du Montcel S, Mendizabai H, Ayme S, Levy A, Philip N. Prevalence of 22q11 microdeletion (letter). J Med Genet 1996;33:719.

19. McDonald-McGinn DM, Kirschner R, Goldmuntz E, Sullivan K, Eicher P, Gerdes M, Moss E, Solot C, Wang P, Jacobs I, Handler S, Knightly C, Heher K, Wilson M, Ming JE, Grace K, Driscoll D, Pasquariello P, Randall P, Larossa D, Emanuel BS Zackai EH. The Philadelphia story. The 22q11.2 deletion: report on 250 patients. Genet Couns 1999;10:11-24.

20. Shprintzen RJ. Velo-cardio-facial syndrome: a distinctive behavioral phenotype. Ment Retard Dev Disabil Res Rev 2000;6:142-147.

21. Mitnick RJ, Bello JA, Shprintzen RJ. Brain anomalies in velo-cardio-facial syndrome. Am J Med Genet 1994;54:100-106.

22. Lynch D, McDonald-McGinn D, Zackai E. Cerebellar atrophy in a patient with velocardiofacial syndrome. J Med Genet 1995;32:561-563.

23. Bingham PM, Zimmerman RA, McDonald-McGinn D, Driscoll D, Emanuel B, Zackai E. Enlarged Sylvian fissures in infants with interstitial deletion of chromosome 22q11. Am J Med Genet 1997;74:538-543.

24. Eliez S, Schmitt JE, White C, Reiss AL. Children and adolescents with Velocardiofacial syndrome: a volumetric MRI study. Am J Psychiatry 2000;157:409-415.

25. Golding-Kushner KJ, Weller G, Shprintzen, RJ. Velo-cardio-facial syndrome: language and psychological profiles. I Craniofac Genet Dev Biol 1985;5:259-266.

26. Swillen A, Devriendt K, Legius E, Eyskens B, Dumoulin M, Gewillig M, Fryns JP. Intelligence and psychosocial adjustment in VCFS: a study of 37 children and adolescents with VCFS. J Med Genet 1997;34:453-458.

27. Papolos DF, Daedda GL, Veit S, Goldberg R, Morros B, Kucherlapati R. Bipolar spectrum disorders in patients diagnosed with velocardiofacial syndrome: does a hemizygous deletion of chromosome 22q11 result in bipolar affective disorder? Am J Psychiatry 1996;153:1541-1547.

28. Jessani N, Weller E, Weller R. Psychiatric syndromes in children and adolescents with velo-cardio-facial syndrome. Paper presented at the Second International Conference on 22q11.2 Deletion; Philadelphia, June 22-25, 2000.

29. Carlson C, Papolos D, Pandita RK, Faedda GL, Veit S, Goldberg R, Shprintzen R, Kucherlapti R, Morrow B. Molecular analysis of velo-cardio-facial syndrome patients with psychiatric disorders. Am J Med Genet 1997;60:851-859.

30. Shprintzen RJ, Goldberg R, Golding-Kushner KJ, Marion RW. Late-onset psychosis in the velo-cardio-facial syndrome (Letter). Am J Med Genet 1992;42:141-142.

31. Bassett AS, Chow EWC, Scutt L, Chiu L, Hodgkinson K, Weksberg R. Psychiatric phenotype of 22q11 deletion in adults. Paper presented at the Second International Conference on 22q11.2 Deletion; Philadelphia, June 22-25, 2000.

32. Kozma C. On cognitive variability in velocardiofacial syndrome: profound mental retardation and autism. Am J Med Genet 1998;81:269-270.

33. Woodin MF, Wang P, Bearden C, McDonald-McGinn D, Zackai E, Emanuel B, Moss E. The principal identifying psychosocial and adaptive features of children with velocardiofacial syndrome and nonverbal learning disorder. Paper presented at the Annual Meeting of the International Neuropsychological Society; Denver, CO. February 12-15, 2000.

34. Bearden CE, Woodin MF, Moss E, Wang P, Driscoll D, Emanuel BS, McDonaldMcGinn DM, Cannon TD, Zackai EH. The neurocognitive and psychosocial profile in children with a 22q11.2 deletion. Poster presented at the Annual Meeting of the American Society of Human Genetics; San Francisco, October 1999.

35. Moss E, Wang PP, McDonald-McGinn DM, Gerdes M, DaCosta AM, Christensen KM. Characteristic cognitive profile in patients with a 22q11.2 deletion: verbal IQ exceeds nonverbal IQ. Am J Hum Genet 1995;57(Suppl):A20.

36. Solot CB, Knightly C, Handler S, Wang PP, Gerdes M, Moss EM, Woodin MF, Mcdonald-McGinn D, Driscoll D, Emanuel B, Zackai E. Communication disorders in children with 22q11.2 microdeletion syndrome. J Commun Disord 2000;33:187204.

37. Wang PP, Woodin MF, Kreps-Falk R, Bearden CE, Moss EM. Spatial memory is impaired in velocardiofacial/DiGeorge syndrome. Paper presented at the 17th Annual Meeting of the Society for Developmental and Behavioral Pediatrics; Seattle, September 1999.

38. Rourke BP. Syndrome of nonverbal learning disabilities: neurodevelopmental manifestations. New York: Guilford Press, 1995

39. Kates WR, Burnette CP, Kaufmann WE, Pearlson GD. The association between white matter anomalies and cognitive functioning in velocardiofacial syndrome. Paper presented at the Second International Conference on 22q11.2 Deletion; Philadelphia, June 22-25, 2000

40. Wechsler D. Wechsler intelligence scale for children. 3rd ed. San Antonio, TX: The Psychological Corporation, 1991.

41. Wechsler D. Wechsler preschool and primary scale of intelligence-revised. San Antonio, TX: The Psychological Corporation, 1989.

42. Wechsler D. Wechsler adult intelligence scale-revised. San Antonio, TX: The Psychological Corporation, 1981.

43. Wechsler individual achievement test. San Antonio, TX. The Psychological Corporation, 1992.

44. Woodcock RW, Johnson MB. Woodcock-Johnson tests of achievement-revised. Allen, TX. DLM Teaching Resources, 1990

45. Reitan RM, Wolfson D. Neuropsychological evaluation of older children. Tucson, AZ: Neuropsychology Press, 1992.

46. Sheslow D, Adams W. Wide range assessment of memory and learning. Wilming ton, DE: Wide Range Incorporated, 1990

47. Achenbach TM. Manual for the child behavior checklist/4-18 and 1991 Profile. Burlington, VT: University of Vermont, Department of Psychiatry, 1991.

48. Flint J. Annotation. Behavioural phenotypes: a window onto the biology of behaviour. J Child Psychol Psychiatry 1999;4:355-367.

49. Flint J. Invited review: the genetic basis of cognition. Brain 1999;122:2015-2031.

50. Plomin R, Owen MJ, McGuffin P. The genetic basis of complex human behaviors. Science 1994;264:1733-1739.

51. Denkla MB. Overview. Specific behavioral/cognitive phenotypes of genetic disorders. Ment Retard Dev Disabil Res Rev 2000;6:81-83.

52. Woodin MF, Moss EM, Swillen A, Wang PP. Neuropsychological and educational interventions. Paper presented at the Second International Conference on $22 \mathrm{q} 11.2$ Deletion; Philadelphia, June 22-25, 2000.

53. Finucane B. Educating the educators about the importance of etiological diagnoses. Paper presented at the Second International Conference on 22q11.2 Deletion; Philadelphia, June 22-25, 2000. 